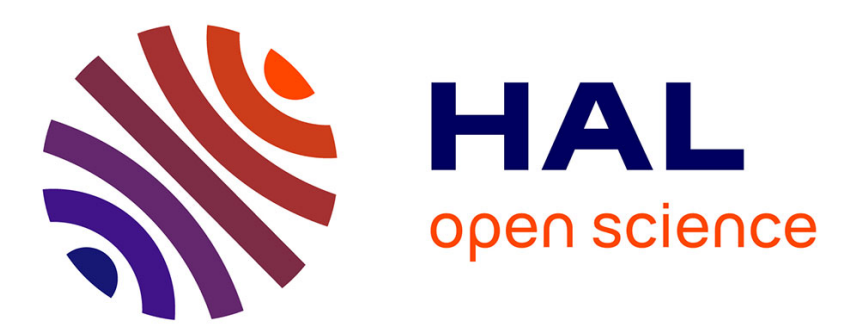

\title{
A new mathematical model for optimizing the combination between antiangiogenic and cytotoxic drugs in oncology
}

Sébastien Benzekry, Guillemette Chapuisat, Joseph Ciccolini, Alice Erlinger, Florence Hubert

\section{To cite this version:}

Sébastien Benzekry, Guillemette Chapuisat, Joseph Ciccolini, Alice Erlinger, Florence Hubert. A new mathematical model for optimizing the combination between antiangiogenic and cytotoxic drugs in oncology. Comptes rendus de l'Académie des sciences. Série I, Mathématique, 2012, 350, pp.23-28. 10.1016/j.crma.2011.11.019 . hal-00641476v2

\section{HAL Id: hal-00641476 \\ https://hal.science/hal-00641476v2}

Submitted on 6 Feb 2012

HAL is a multi-disciplinary open access archive for the deposit and dissemination of scientific research documents, whether they are published or not. The documents may come from teaching and research institutions in France or abroad, or from public or private research centers.
L'archive ouverte pluridisciplinaire HAL, est destinée au dépôt et à la diffusion de documents scientifiques de niveau recherche, publiés ou non, émanant des établissements d'enseignement et de recherche français ou étrangers, des laboratoires publics ou privés. 


\title{
A new mathematical model for optimizing the combination between antiangiogenic and cy- totoxic drugs in oncology
}

\author{
Sébastien Benzekry $^{*}$ - Guillemette Chapuisat ${ }^{* *}-$ Joseph Ciccolini $^{* * *}$ \\ - Alice Erlinger* _ Florence Hubert* \\ * LATP, UMR CNRS 6632, Aix-Marseille Université, 39 rue F.-Joliot-Curie, F-13453 \\ Marseille cedex 13, France \\ ** LATP, UMR CNRS 6632, Aix-Marseille Université, av. Escadrille Normandie- \\ Niemen F-13397 Marseille Cedex 20, France \\ *** CRO2, UMR 911, Aix-Marseille Université, 27 bld Jean-Moulin, F-13385 Mar- \\ seille cedex 05, France
}

Abstract. We present in this paper a new mathematical model designed to optimize and to rationalize the association between cytotoxic and antiangiogenic drugs in the treatment of a primary tumor. This model takes into account the non-linear interlinkings between both drugs. In particular, this original model integrates the influence of the vasculature state on the delivery of the drugs to the tumor. In the future, this model could be used in clinical oncology to optimize antiangiogenic-based combinational regimen so as to ensure a maximum efficacy.

Résumé. $\quad$ Nous proposons ici un nouveau modèle mathématique dédié à l'optimisation thérapeutique des combinaisons antiangiogéniques/cytotoxiques en cancérologie. Ce modèle permet de rendre compte des interactions non-linéaires entre les deux traitements et notamment de l'influence de l'état de la vasculature sur l'accès à la tumeur des molécules administrées. A terme, ce modèle pourra être utilisé en oncologie clinique pour piloter les protocoles chimiothérapeutiques reposant sur la combinaison d'un antiangiogénique et de médicaments cytotoxiques, afin d'en améliorer l'efficacité antitumorale.

Keywords: Cancer modelling, therapy modelling

\section{Version française abrégée}

La découverte du phénomène d'angiogénèse tumorale par J. Folkman [8] en 1971 a permis la mise en place de traitements antiangiogéniques des cancers et préfigure l'avènement des thérapies dites ciblées, au début des années 2000. Ces traitements sont généralement administrés en parallèle avec un ou plusieurs agents cytotoxiques classiques. Les agents cytotoxiques inhibent la réplication tumorale en induisant une mort cellulaire, le plus souvent de nature apoptotique. Les antiangiogéniques, en interférant avec les voies de signalisation impactant sur la formation de néo-vaisseaux, diminuent l'apport de nutriments et d'oxygène à la tumeur et limitent ainsi sa crois- 
sance. En combinant les deux, on peut espérer avoir un effet synergique. Toutefois, en pratique clinique, les associations thérapies ciblées/cytotoxiques reposent, dans leurs modalités d'administration, essentiellement sur des considérations pratiques et logistiques liées au protocole chimiothérapeutique choisi et à la présence effective du patient dans le service. Or, en affectant la vasculature tumorale, il n'est pas impossible qu'un traitement antiangiogénique freine également le bon accès au site d'action des cytotoxiques co-administrés. Dans ce contexte, on peut emmettre l'hypothèse qu'il existe une modalité optimale d'association entre ces deux types de traitements. Nous proposons ici un modèle mathématique qui permet de rendre compte de l'état du réseau vasculaire de la tumeur (influencé par le traitement antiangiogénique) sur l'apport et donc l'efficacité des médicaments. Il est centré sur les équations suivantes :

$$
\left\{\begin{array}{l}
\frac{d n}{d t}(t)=\lambda n(t) \log \left(\frac{s(t)}{n(t)}\right)-k q(t) s(t) C(t) n(t) \\
\frac{d s}{d t}(t)=\chi u(t)-\tau s(t) \\
\frac{d u}{d t}(t)=-\chi u(t)+\gamma n(t)-\delta n(t)^{\frac{2}{3}} u(t)-\eta q(t) s(t) A(t) u(t)
\end{array}\right.
$$

où $n$ représente le nombre de cellules tumorales, $s$ la quantité de vaisseaux stables, $u$ la quantité de vaisseaux instables, $q$ la qualité de la vasculature, $C$ la concentration effective en agent cytotoxique et $A$ la concentration effective en agent antiangiogénique. Ces équations sont dérivées des modèles de Gompertz [9] et de Hahnfeldt et al. [10]. Les concentrations effectives sont calculées à l'aide de modèles pharmacocinétiques et pharmacodynamiques [2].

En résolvant numériquement ce modèle dans le cas d'une thérapie couplée etoposide oral et bevacizumab, on constate effectivement qu'à dose égale, le délai entre l'administration des différents agents influence fortement l'impact du traitement sur la croissance tumorale (fig. 1). Il semble plus intéressant d'administrer l'agent antiangiogénique en premier afin qu'il améliore la qualité de la vasculature avant d'administrer l'agent cytotoxique. En cela, on retrouve les conclusions de Jain [12]. On peut alors chercher numériquement le délai optimal pour minimiser la taille minimale de la tumeur (fig. 2). On obtient une durée de 6 à 7 jours correspondant à l'intervalle optimal d'utilisation séquentielle des deux molécules. Certains paramètres du modèle ayant été fixés arbitrairement, les résultats numŕiques présentés ici ne peuvent être directement transférés en clinique mais il apparaît clairement que le calcul de la posologie optimale (doses et temps d'administration) pour ces traitements couplés pourrait grandement impacter l'efficacité de ces thérapies.

\section{Introduction}

A cancer is an abnormal cell proliferation within a tissue. This proliferation is generally due to genetic mutations in a single normal cell leading to dysregulation of the cell division and inability to undergo programmed cell-death or apoptosis. The resulting dividing cells can form a tumor localised to the organ (primary tumor) or subsequently disseminate throughout the body (secondary tumor or metastases). Here we will consider the antiproliferative effect of a combined therapy on the growth of a 
primary tumor only.

Conventional treatments consist in blocking cell division and eventually killing cancer cells with cytotoxic agents. Such agents act on all rapidly dividing cells, i.e. most tumor cells as well as bone marrow, intestinal or folicles. Thus, they have numerous and possibly life-threatening side effects which frequently require a decrease in dosing or treatment discontinuation until the patient recovers.

Another therapeutic possibility takes advantage of oxygen and nutrient requirements for proper tumor growth. Oxygen and nutrients being supplied by blood, tumors develop new blood vessels to ensure their growth. This process, termed tumor angiogenesis, was discovered in the 1970's by Judah Folkman [8]. Without angiogenesis, admittedly the size of most primary tumors would not exceed $2-3 \mathrm{~mm}$. To promote new vessels formation, cancer cells secrete specific growth factors like VEGF (Vascular Endothelial Growth Factor). These factors bind to receptors on vascular endothelial cells and stimulate their proliferation and migration to the tumor. Several other exocrine factors like PDGF, SDF1, PIGF or FGF2 are now recognized as regulating the neo-angiogenic process in the tumor environment. This discovery led to the new era of antiangiogenic therapies, whose purpose is to inhibit new vessels formation and thus tumor growth ultimately. To date, the humanized monoclonal antibody bevacizumab is the only marketed drug that acts directly as an antiangiogenic agent by targeting circulating VEGF, thus preventing it to reach its receptor and to promote neoangiogenesis. Bevacizumab has been approved for treating breast and colorectal cancers in combination with various cytotoxics, and is currently under clinical investigations in a variety of solid tumors like lung cancer. In this paper, bevacizumab will be used as the paradigm of antiangiogenic drugs.

Our aim is to develop a mathematical model describing a combinational therapy using a cytotoxic agent (we have chosen etoposide) and bevacizumab in a localized tumor. The originality of our model is to take into account the interactions between the two drugs, in particular the influence of the quantity and quality of the vasculature on the delivery of the drugs to the tumor.

\section{Model}

Our model of combination therapy is based on already well known models. We have chosen to start from the classical model of tumor growth of Gompertz [9] where the number of cancer cells $n$ follows the law

$$
\frac{d n}{d t}(t)=\lambda n(t) \ln \left(\frac{\theta}{n(t)}\right)
$$

with $\theta$ a constant which we will call carrying capacity. This constant represents the maximal size the tumor could reach. This original model does not take into account the process of angiogenesis. That is why Hahnfeldt et al. [10] have proposed a modification of the Gompertz model which considers the carrying capacity as a variable 
linked to the size of the vasculature at the given time and no longer as a constant. Equation (1) becomes

$$
\frac{d n}{d t}(t)=\lambda n(t) \ln \left(\frac{\theta(t)}{n(t)}\right) .
$$

In Hahnfeldt's model, the dynamics of the carrying capacity is the result of a balance between a term of stimulation of the vasculature by the tumor cells and a term of inhibition. Indeed, without inhibition, the vasculature would become anarchical and inefficient for tumor growth. Thus

$$
\frac{d \theta}{d t}(t)=b n(t)-d n(t)^{\frac{2}{3}} \theta(t) .
$$

It remains to add the effects of combination of the cytotoxic (CT) and the antiangiogenic (AA) agents. A pharmacokinetic and pharmacodynamic approach as the one developed in [2] is necessary to link the doses of drugs administred to their effective concentrations. We denote $\mathrm{C}(\mathrm{t})$ the effective concentration of $\mathrm{CT}$ and $\mathrm{A}(\mathrm{t})$ the effective concentration of AA.

Since the cytotoxic agent decreases tumor growth rate, the tumor growth equation (2) becomes

$$
\frac{d n(t)}{d t}=\lambda n(t) \log \left(\frac{\theta(t))}{n(t)}\right)-k C(t) n(t)
$$

For its part, the antiangiogenic drug adds an inhibition term in the evolution of the carrying capacity and equation (3) becomes

$$
\frac{d \theta}{d t}(t)=b n(t)-d n(t)^{\frac{2}{3}} \theta(t)-e A(t) \theta(t)
$$

However, the model (4)-(5) does not allow to assess the interactions between the two treatments and in particular the influence of the vasculature state on the delivery of CT and AA to the tumor. To take into account such interactions, we propose a modification of this model that consists in separating the vasculature into stable (mature) and unstable (immature) vessels.

Variables. We denote in the sequel $n$ the number of cancer cells, $s$ and $u$ variables related respectively to the density of stable and unstable vessels. Let $C$ and $A$ be the effective concentrations of cytotoxic agent and of antiangiogenic agent.

Biological hypotheses. Our model is build from the Hahnfeldt et al. model (2), (3) with the following additional assumptions on the vasculature. Only stable vessels supply nutrients and oxygen, $s$ will thus substitute for the carrying capacity $\theta$ of Hahnfeldt's model. Only stable vessels supply pharmacological agents. Only unstable vessels are subjected to stimulatory and inhibitory signals coming from the tumor. Unstable vessels maturate with a constant rate denoted by $\chi$, stable vessels are subject to natural death (apoptosis) with a rate $\tau$.

For the dynamics of the therapy, we assume moreover that the effects of the agents are proportional to their effective concentration but with a constant depending on the 
density of the vasculature and on the quality of this vasculature. The antiangiogenic agent bevacizumab acts as a vessel disruptive agent only on immature vessels. The quality of the vasculature for distributing the pharmacological agents depends on the proportion of stable vessel in the vasculature. Let us introduce the function $q(t)=$ $\frac{s(t)}{s(t)+u(t)}$, to describe this quality of the vasculature

Equations. Starting from these biological hypotheses, the equations of our model are

$$
\left\{\begin{aligned}
\frac{d n}{d t}(t) & =\lambda n(t) \log \left(\frac{s(t)}{n(t)}\right)-k q(t) s(t) C(t) n(t) \\
\frac{d s}{d t}(t) & =\chi u(t)-\tau s(t) \\
\frac{d u}{d t}(t) & =-\chi u(t)+\gamma n(t)-\delta n(t)^{\frac{2}{3}} u(t)-\eta q(t) s(t) A(t) u(t)
\end{aligned}\right.
$$

Parameter values. The parameter values used in the illustrations below are fixed to reproduce the growth of a human tumor in absence of treatment like in [11]. We set $\lambda=4.2 \times 10^{-3}, \chi=7.56 \times 10^{-3}, \tau=7.5 \times 10^{-3}, \gamma=1$ and $\delta=5.73 \times 10^{-8}$.

The parameters $k$ and $\eta$ as well as the effective concentrations $C(t)$ and $A(t)$ depend on the chosen therapy. In the following, we opted for oral etoposide and bevacizumab. The cytotoxic agent etoposide follows a one-compartment pharmacokinetic model as described by Jong et al. [13], the effective concentration $C(t)$ being the concentration in this compartment above a threshold. The antiangiogenic agent follows a two-compartment pharmacokinetic model as described by Bruno et al. [6], the effective concentration $A(t)$ being the concentration in the second compartment above a threshold. The linear ordinary differential equations obtained with this approach will not be described here (see [2] or [5] for more details). We arbitrarily fixed $k=1.37 \times 10^{-9}$ and $\eta=6.85 \times 10^{-11}$ in order to obtain realistic drug effects.

\section{Illustrations}

We investigate in this section the performance of this new model for studying the interactions between etoposide and bevacizumab, depending on the way the drugs are given. To support our hypothesis, we have chosen to simulate the impact of variations in time interval between the administrations of bevacizumab and oral etoposide, a regimen that has been tested recently to treat glioblastomas. In section 3.1, we will illustrate the effect of two distinct protocols on the tumor and its vasculature. In section 3.2, we will further show how our model allows to optimize the administration of the drugs in a given protocol.

\subsection{Evolution of tumor size and vessels during a cycle of chemotherapy}

Current combinational therapies are administered as successive courses, whom frequency and duration are mostly limited by a Maximal Tolerated Dose (MTD), when 
it is not by logistic considerations such as availability of the patient in the medical unit. Although dosage and periodicity of the courses (ie, usually from one to three weeks) are supposed to remain the same for a given protocol, frequent changes occur due to appearance of treatment-related toxicities in patients that require delay in the administration of the forthcoming courses, or reduction in dosage. In addition, a same protocol can be administered following a wide range of modalities, thus leading to numerous variations. Overall, it is widely acknowledged now that most anticancer regimen are administered on a rather empirical basis [7, 14].

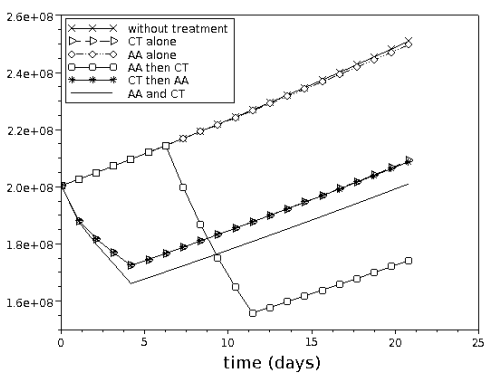

(a) Number of tumor cells

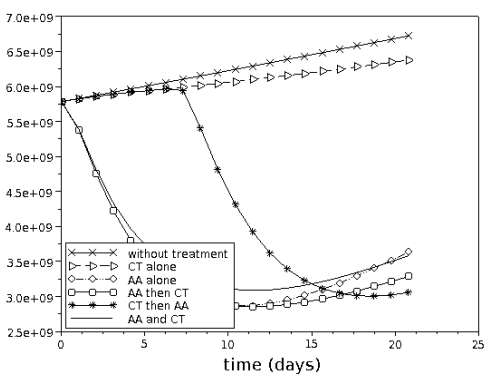

(c) Unstable vessels

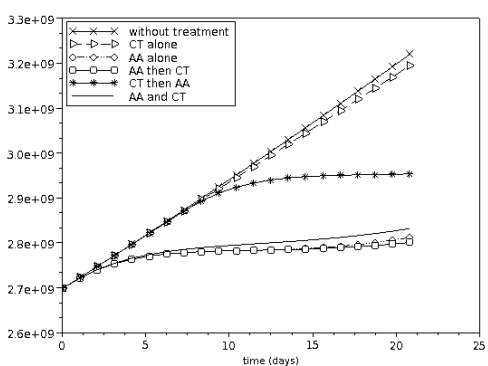

(b) Stable vessels

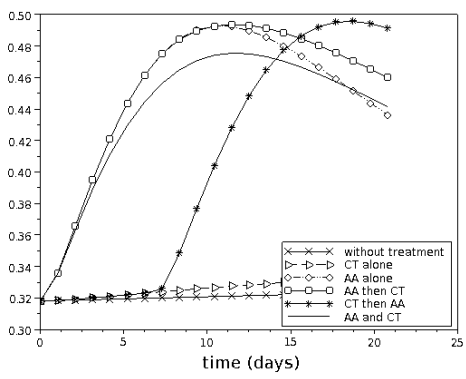

(d) Quality of vasculature

Figure 1. Evolution of tumor size, quantity of stable and unstable vessels, and quality of vasculature in six different protocols. Without treatment: no drug is administered. CT alone: oral etoposide is administered from day 1 to day 5 but no antiangiogenic agent is given. AA alone: bevacizumab is administered on day 1 but no cytotoxic agent is given. AA then CT: bevacizumab is administered on day 1 followed by the administration of oral etoposide from day 8 to day 13. CT then AA: oral etoposide is administered from day 1 to day 5 followed by the administration of bevacizumab on day 8. AA and CT: oral etoposide is administered from day 1 to day 5 and bevacizumab is given on day 1. 
With our model, we have simulated the evolution in size of a given tumor over a course of 21-days with different drugs. Our main focus was the impact of the wait between etoposide and bevacizumab administrations on treatment efficacy, rather than the impact of the drug dosage. Thus every time the AA agent is administred, $525 \mathrm{mg}$ of bevacizumab is given as a short infusion. Concerning the CT agent, the patient takes orally $212 \mathrm{mg}$ a day during five consecutive days.

Figure 1 presents the results of our model when no treatment is given, when a single agent (AA or CT) is given, when both agents are given simultaneously and when both agents are given with a delay of one week between the administrations (AA then CT and CT then AA). The posology has obviously a strong influence on the final size of the tumor and even when both drugs are given, the issue of the treatment depends strongly on the order the drugs are given. With this model, the treatment that obtains the best results consists in giving bevacizumab first and etoposide one week later.

These results are consistent with the observations of Jain in [12]. In this paper, Jain assumes that in a first concentration range, bevacizumab could lead to a normalisation of the vasculature, hence to a better delivery of etoposide. In the same paper, he claims also that, in a higher concentration range, bevacizumab could disrupt most of the vasculature and thus impair the delivery of etoposide, we have not tested this fact yet. Figures 1(b) and 1(d) shows that, in the concentration range we have used, bevacizumab significantly increases the quality of the vasculature without disrupting all stable vessels which deliver etoposide.

The final purpose of this model is to provide an insight on how both drugs can be best combined to ensure a maximum efficacy. Once the model is set up, in silico simulations can help to predict the various effects on tumor growth reduction, so as to chose the best regimen. In this feasibility study, our data strongly suggest that the best sequence is antiangiogenic followed by the cytotoxic agent.

\subsection{Optimization of the time interval between the administrations of bevacizumab and of etoposide}

We are now interested in optimizing the effect of the combination therapy by adjusting the delay between the administrations of both agents. The agents are given with the same dosage as in the previous section. As suggested by the preceding results, bevacizumab is given first to normalize the vasculature. Figure 2(a) shows the evolution of the tumor during 3 cycles of combination therapy for various delay in the administration of both agents and figure 2(b) shows the minimum size of the tumor over the 3 cycles depending on the delay between the administration of both agents. On this figure, we observe that the best delay is about one week. This optimal delay may depend on the parameter values (specially on $k$ and $\eta$ which were fixed arbitrarily) but it seems that there always exists a minimum. 


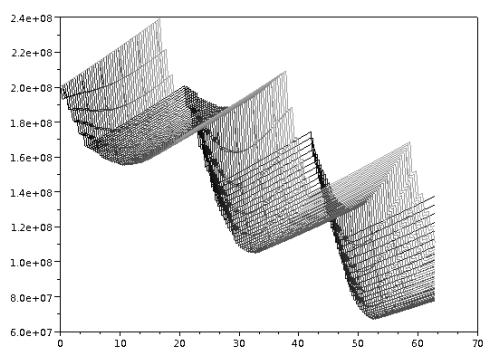

(a) Evolution of the tumor size

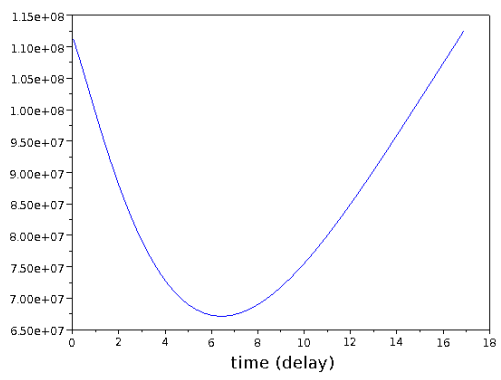

(b) Minimum tumor size depending on the delay

Figure 2. Optimization of the combination therapy. Bevacizumab is administered on day 1 and etoposide is administered during 5 days after a delay of 0 to 17 days.

\section{Conclusion and perspectives}

This work is a novel approach to describe the effects of a combination between cytotoxic and antiangiogenic agents. Its originality is to take into account the nonlinear interlinkings between the two drugs. Our illustrations clearly show that this new model is able to describe a part of these interlinkings and that the consequences of these effects should not be neglected when a protocol of combination therapy is established.

For now, the model, beside the description of the effects of the combination on tumor growth, can be used to optimize and to rationalize the association between antiangiogenic and cytotoxic drugs. But in this preliminary study, we have used a set of parameter values which should be adjusted to each individual patient. A sensitivity study of these parameters will have to be carried out and set against non-clinical data obtained in mice, so as to adjust the model.

An interesting feature will be to further extend this approach to the treatment of metastatic cancer as in $[1,3,4,5]$.

\section{References}

[1] D. Barbolosi, A. Benabdallah, F. Hubert, and F. Verga, Mathematical and numerical analysis for a model of growing metastatic tumors, Math. Biosci. 218 (2009), 1-14.

[2] D. Barbolosi, G. Freyer, J. Ciccolini, A. Iliadis, Optimisation de la posologie et des modalités d'administration des agents cytotoxiques à l'aide d'un modèle mathématique, Bulletin du Cancer 90 (2003) 167-75. 
[3] D. Barbolosi, F. Verga, A. Benabdallah, F. Hubert, C. Mercier, J. Ciccolini, and C. Faivre, Modélisation du rique d'évolution métastatique chez les patients supposés avoir une maladie localisée, Oncologie 13 (2011), 528-533.

[4] S. Benzekry, Mathematical and numerical analysis of a model for antiangiogenic therapy in metastatic cancers, M2AN 46 (2012) 207-237.

[5] S. Benzekry, N. André, A. Benabdallah, J. Ciccolini, C. Faivre, F. Hubert and D. Barbolosi, Modelling the impact of anticancer agents on metastatic spreading, MMNP (2011), in press.

[6] R. Bruno, N. Vivier, J. C. Vergniol, S. L. De Phillips, G. Montay, and L. B. Sheiner, A population pharmacokinetic model for docetaxel (Taxotere): model building and validation, J Pharmacokinet Biopharm 24 (19996) 153-172.

[7] J.M. Davies, R.M. Goldberg, Treatment of metastatic colorectal cancer, Semin Oncol. 38 (2011) 552-560.

[8] J. Folkman, Tumor angiogenesis: therapeutic implications, New England Journal of Medicine 285 (1971) 1182-1186.

[9] B. Gompertz, On the nature of the function expressiv of the law of human mortality and on a new mode of determining the value of life contigencies, Phil. Trans. Royal Soc. of London 115 (1825) 513-583.

[10] P. Hahnfeldt, D. Panigraphy, J. Folkman, L. Hlatky, Tumor development under angiogenic signaling: A dynamical theory of tumor growth, treatment response, and postvascular dormancy, Cancer Research 75 (1999) 4770-4775.

[11] K. Iwata, K. Kawasaki, N. Shigesad, A dynamical model for the growth and size distribution of multiple metastatic tumors, J. Theor. Biol. 203 (2000) 177-186.

[12] R.K. Jain, Molecular regulation of vessel maturation, Nature Medicine 9 (2003) 685-693.

[13] R.S. de Jong, N.H. Mulder, D.R.A. Uges, S. Kaul, B. Winograd, D.T. Sleijfer, H.J.M. Groen, O.H.B. Willemse, Randomized comparison of etoposide pharmacokinetics after oral etoposide phosphate and oral etoposide, British Journal of Cancer 75 (1997) 1660-1666.

[14] D. Sargent, A. Grothey, Sound footing or slippery slope? The value of secondary analyses of randomized trials, J Clin Oncol. 25 (2007) 3191-3193. 